\title{
Evolution Process of Liquefied Natural Gas from Stratification to Rollover in Tanks of Coastal Engineering with the Influence of Baffle Structure
}

\author{
Zhe Wang ${ }^{1,2}\left(\mathbb{D}\right.$, Fenghui Han ${ }^{1,3, *}$, Yuxiang Liu ${ }^{1}$ and Wenhua Li ${ }^{1,3}$ \\ 1 Marine Engineering College, Dalian Maritime University, Dalian 116026, China; \\ zhe.wang.work@gmail.com (Z.W.); 1120201130@dlmu.edu.cn (Y.L.); 1wh992@dlmu.edu.cn (W.L.) \\ 2 International Center on Energy Sustainable Ships and Ports, Dalian 116026, China \\ 3 National Center for International Research of Subsea Engineering Technology and Equipment, \\ Dalian Maritime University, Dalian 116026, China \\ * Correspondence: fh.han@dlmu.edu.cn; Tel.: +86-0411-84729038
}

check for

updates

Citation: Wang, Z.; Han, F.; Liu, Y.; Li, W. Evolution Process of Liquefied Natural Gas from Stratification to Rollover in Tanks of Coastal Engineering with the Influence of Baffle Structure. J. Mar. Sci. Eng. 2021, 9, 95. https://doi.org/10.3390/ jmse9010095

Received: 17 December 2020 Accepted: 13 January 2021 Published: 17 January 2021

Publisher's Note: MDPI stays neutral with regard to jurisdictional clai$\mathrm{ms}$ in published maps and institutional affiliations.

Copyright: $(\odot 2021$ by the authors. Licensee MDPI, Basel, Switzerland. This article is an open access article distributed under the terms and conditions of the Creative Commons Attribution (CC BY) license (https:// creativecommons.org/licenses/by/ $4.0 /)$.

\begin{abstract}
During the storage process, liquefied natural gas (LNG) may undergo severe evaporation, stratification, and rollover in large storage tanks due to heat leakage, aging, or charging, causing major safety risks. Therefore, this article theoretically analyzes the causes and inducing factors of the LNG stratification and rollover phenomenon in the storage tank of coastal engineering. The computational fluid dynamics was used to establish a numerical model for the heat and mass transfer of LNG multicomponent materials in the imaginary layered interface of the storage tank, and the evolution process of LNG from spontaneous stratification to rollover was simulated. The accuracy of the mathematical model is verified by comparing numerical results with experimental data from open literature. The effects of the density difference between upper and lower layers, layering parameters, heat leakage parameters, and the baffles structure on the rollover process were studied. The effects of the interfacial surface variations are not included in this study. The results show that different baffle structures will form different boundary velocity fields, which will only affect the severity of the rollover, not the occurrence time. The larger the layering density difference, the earlier the rollover occurs. Under current conditions, the baffle structure that has the best suppression of rollover and the minimum boundary velocity is at $0.5 \mathrm{~m}$ above the stratified interface with the installation of the baffle at 5 degrees.
\end{abstract}

Keywords: coastal LNG engineering; storage tank; evolution process; stratification; rollover; baffle structure

\section{Introduction}

Natural gas is an important energy carrier in the post-petroleum era. Because of its large reserves, less polluting, and efficient conversion, natural gas has become the main pillar of the world's energy [1,2]. In order to facilitate storage and long-distance transportation like petroleum, natural gas is usually liquefied to form liquefied natural gas (LNG) at atmospheric pressure at $-162{ }^{\circ} \mathrm{C}$ after removing water, carbon dioxide and heavy hydrocarbons using adsorption and separation. Its volume is $1 / 600$ of the gaseous state; its density is 600 times that of the standard state, and its weight is only $45 \%$ compared with the same volume of water [3,4]. LNG not only improves the efficiency of natural gas storage and transportation but also can recover natural gas resources in remote areas and make reasonable use to reduce resource waste. Therefore, canned land transportation and LNG transport by ocean-going freighter have become important forms of international energy trade [5]. According to the forecast of the global LNG outlook [6], global energy demand from 2019 to 2035 , more than $40 \%$ will be supplied by LNG, and its output will maintain an annual growth rate of more than $4 \%$. Since LNG is a multicomponent mixture mainly dominated by methane, the relevant thermophysical properties (density, boiling 
point, temperature and pressure) vary slightly depending on the origin [7]. In the process of transportation and storage of LNG, the unstable storage phenomenon caused by the violent evaporation of the liquid is prone to occur in the storage tank. This phenomenon is the layered rollover, and the stratification is the direct cause of the instability rollover $[8,9]$. The delamination of LNG refers to the formation of two liquid layers with different densities in the upper and lower tanks. According to previous research [10-12], there are three main reasons. (1) Impurity aging: LNG contains nitrogen impurities. The molecular weight of impurities is greater than the LNG components, and the boiling point is lower than the boiling point in LNG. Therefore, in the process of evaporation, impurities evaporate before other components, and the evaporation rate of impurities in the storage tank will produce different layers. (2) Infiltration of external heat: under the influence of heat leakage from the bottom and sidewalls of the storage tank, the temperature of the liquid in the lower layer rises, and the density decreases. The strength of the LNG movement in the storage tank is not sufficient to allow the upper and lower liquids to mix uniformly in a short time. Thermal convective motion exists in the respective layers, thereby forming an unstable layer with a high-density in the upper layer and a low-density in the lower layer. (3) Improper filling method: artificially fill the storage tank with LNG, which is different from the original temperature and composition. Filling LNG with a density higher than the original liquid by using the top-feed method or filling LNG with a lower density than the original liquid by using the bottom-feed method these conditions are liable to form an unstable stratification in the storage tank. At present, limited measures can be taken, such as more stringent processes to filter impurities, artificially control the filling rate, and appropriate and effective methods to avoid the stratification caused by reasons 1 and 3. However, due to the existence of a large temperature difference, the natural heat penetration of the storage tank is difficult to eliminate, so the layering caused by reason 2 is inevitable at this stage.

As there have been several serious LNG rollover accidents in storage tanks in history $[13,14]$, so many researchers have used theoretical models, experimental studies, and numerical simulations to study the mechanism and preventive measures in the evolution process of LNG from stratification to rollover in tanks [15]. The development of theoretical models has undergone the development process of two-stage models [16,17], three-stage models [18,19], four-stage models [20] and other models [21,22]. These models range from the original interface-based static and two-component assumptions to the current nonsteady-state interfaces, multicomponent multi-variable, and other processes. They gradually systematically and theoretically simulate the simulation of layering and rolling of LNG storage tanks, which are increasingly similar to the actual situation. The prediction of the phenomenon of stratification and rollover of LNG in storage tanks is becoming increasingly accurate.

For the experimental study of related phenomena, Sugawara et al. [23] studied the layered rollover phenomenon of LNG from different origins with a $500 \mathrm{~mm}$ diameter tank. The fact that the interface accelerates down before rolling is verified by experiments. Muro et al. [24] used methane, ethane, propane and other layered liquids to conduct experiments in stainless steel vacuum storage tanks to study the relationship between evaporation rate and fluid superheating. Marcel et al. [25] used a scrapped LNG storage tank to perform a rollover experiment, which proved that the interface at the initial stage of the layering was basically stationary, and the interface moved rapidly downward when the rollover occurred. Munakata et al. [26] studied the effect of initial concentration difference on roll time, conducted experiments on cylindrical and rectangular gas storage containers, and found that the mixing strength and interface descent velocity of liquid in cylindrical storage tanks were large and the time was short. Tanasawa et al. [27] performed a tumble experiment in a small-capacity storage tank, using a visual method to record the movement of the boundary layer along the vertical wall surface, and used a shadow photography technique to observe the density distribution in each liquid layer. Bates et al. [28] experimentally studied the evolution process of layered LNG from formation to decomposition. This evolution was 
found to include a stable interface and a migration interface, which migrated over time and eventually flipped. Gorieu et al. [29] introduced how to operate LNG terminals flexibly and safely under the condition of different LNG producing areas and diversified LNG quality. The strict requirements and solutions of the above conditions to the injection objects are analyzed by using the experimental data of manufacturers.

With the rapid development of computer technology, using numerical simulation technology to numerically calculate the heat and mass transfer of a large number of unsteady and complex processes has become an effective method for current research [30,31]. In the numerical simulation, it is possible to simulate the thermophysical process under different working conditions by changing the boundary and initial conditions and obtain a series of results [32]. Zakaria et al. [33] analyzed the heat and pressure distribution of LNG during heat leakage. The simulation involves heat leakage from static storage tanks, bottom and sidewalls. The results show that the maximum pressure point is on the circumference connecting the tank top and the tank sidewall. Degawa et al. [34] carried out a numerical simulation of the effects of different jet angles on the filling of cylindrical storage tanks. Studies have shown that secondary backflow is caused by jets on the horizontal cross-section of the tank, and it consists of a pair of vortices. Zhao et al. [35] proposed a theoretical model of gas-liquid-layered LNG tank rollover based on large eddy simulation and obtained a gas-liquid-layered LNG tank rollover curve model. Wei et al. [36] carried out a numerical study on the interface instability process of multicomponent liquids. The effect of rheological behavior on interface stability was studied. The tumbling process, the variation trend of evaporation rate and temperature distribution were described. Hubert et al. [37] developed a prediction tool for LNG flipping in 3D storage tanks within the framework of OpenFOAM. The results are compared with the experimental tests, and it is found that there is a good consistency between the predicted value and the measured value. The maximum deviation of the roll time and the peak value are less than $15 \%$. Felipe et al. [38] provided a rule of thumb for estimating the temperature of evaporated gas in industrial storage tanks and developed an unbalanced model related to LNG evaporation from large storage tanks at constant pressure. Federica et al. [39] used CFD technology to simulate the self-pressurization behavior of cryogenic storage tanks. The evaporation of ethylene and methane in storage tanks was studied. Ethylene was found to pressurize and vaporize faster than methane. Due to more effective natural convection, the liquid thermal stratification of methane is wider than that of ethylene.

Since LNG will replace oil as the transitional product of green energy, LNG receiving stations and storage tanks have been built in coastal port cities all over the world. Therefore, it is important to study the heat and mass transfer and flow of LNG in storage tanks and understand the mechanism of the relevant processes to prevent the stratification and to tumble of LNG storage tanks due to various factors. In summary, the current numerical simulation studies of the stratified failure and rollover process in the above literature are mainly focused on the LNG storage tanks in the static storage state and the LNG stratification in the storage tanks caused by filling. The effect of heat, or only considering heat leakage, but not changing properties. At the same time, few studies have considered LNG multicomponent, variable physical properties, heat leakage and temperature differences. It is worth noting that there is almost no research on the effect of adding baffle structure in the storage tank on preventing the phenomenon of a rollover after delamination. Therefore, this article considers the multicomponent, variable physical properties, heat leakage, and temperature difference of LNG and establishes a simulation model of rollover caused by the stratification of LNG in a static storage state. The characteristics and mechanism of LNG from stratification to rollover are analyzed. The published literature experimental data and simulation data are used as benchmarks to verify the accuracy of the CFD technique in this paper. Finally, by adding baffles of different structures to the storage tank, the effects of various structures on the rollover phenomenon after LNG layering were studied to obtain the optimal baffle setting. 


\section{Object Description}

\subsection{LNG Thermal Properties Description}

In the process of layering and rolling, LNG involves the calculation of heat, mass and momentum transfer. Changing the content and temperature of LNG components will have a significant effect on its thermophysical properties, which will, in turn, affect the calculation results of its heat and mass transfer processes. Therefore, an accurate calculation of LNG physical property data is particularly important. The main parameters that affect the heat and mass transfer of LNG are density $\rho$, specific heat capacity $c_{p}$, viscosity $\mu$, and thermal conductivity $\lambda$. Under the influence of heat leakage from the external environment of the storage tank, the LNG temperature in the tank will change, which affects these physical properties. The parameters will also change accordingly. In many kinds of literature, the simulation of the tumbling process mostly sets the physical parameters of LNG to a constant value, neglecting the impact of the environment and discrepancy with the actual situation. In order to solve this problem, this study introduces four fitting polynomials that consider multiple components and variable properties on the assumption of state. As shown in Table 1, the theoretical calculation process of the above four physical parameter polynomials comes from the compound calculation manual [40]. In an appropriate temperature range, the physical parameters of the LNG can be accurately calculated under the assumption that the upper layer is saturated under gas pressure and the lower layer is superheated. Under the temperature ranges and assumptions, the fitted polynomials and the results of thermodynamic properties calculated by ASPEN software using the Peng-Robinson equation of state are compared. Their deviation is between $-4.30 \%$ to $7.22 \%$, which meets the needs of practical application.

Table 1. Liquefied natural gas (LNG) thermophysical correlation and applicable range.

\begin{tabular}{|c|c|c|c|}
\hline Item & Theoretical Derivation & Fitting Formula & Range \\
\hline$\rho\left(\mathrm{kg} / \mathrm{m}^{3}\right)$ & $\rho=\sum_{i=1}^{n}\left(x_{i} \cdot A_{i} \cdot B_{i}^{-\left(1-T / T_{c i}\right)^{n_{i}}} \times 10^{3}\right)$ & $\begin{array}{c}\rho_{u}=21.67 \mathrm{~T}-19,998.39 \\
\rho_{l}=-1.45 \mathrm{~T}+590.12\end{array}$ & $100 \mathrm{~K} \sim 125 \mathrm{~K}$ \\
\hline$c_{p}(\mathrm{~J} / \mathrm{kg} \cdot \mathrm{K})$ & $c_{p}=\sum_{i=1}^{n} x_{i} \cdot\left(A+B T+C T^{2}+D T^{3}\right)$ & $\begin{array}{c}c_{p_{-} u}=-180.36 \mathrm{~T}-23,585.1 \\
c_{p_{-} l}=6.901 \mathrm{~T}+2658.2\end{array}$ & $100 \mathrm{~K} \sim 125 \mathrm{~K}$ \\
\hline$\mu\left(\mathrm{W} / \mathrm{m}^{2} \cdot \mathrm{K}\right)$ & $\mu=\left(\sum_{i=1}^{n} x_{i} \cdot 10^{\left(A+B / T+C T^{2}+D T^{3}\right){ }_{i}^{1 / 3}}\right)^{3}$ & $\begin{array}{l}\mu_{u}=0.0059 \mathrm{~T}-0.4753 \\
\mu_{l}=-0.0013 \mathrm{~T}+0.3392\end{array}$ & $100 \mathrm{~K} \sim 125 \mathrm{~K}$ \\
\hline$\lambda(\mathrm{Pa} \cdot \mathrm{s})$ & $\lambda=\sum_{i=1}^{n} \sum_{j=1}^{n}\left(\frac{x i v i}{x j v j} 2 /\left(\lambda_{i}^{-1}+\lambda_{j}^{-1}\right)\right)$ & $\begin{array}{c}\lambda_{u}=0.00029 \mathrm{~T}+0.031 \\
\lambda_{l}=-0.000002 \mathrm{~T}+0.0004\end{array}$ & $100 \mathrm{~K} \sim 125 \mathrm{~K}$ \\
\hline
\end{tabular}

\subsection{Physical Processes Description}

When LNG is stored for a long time, two or more LNG layers of different temperatures and densities will form. Under the influence of heat and gravity, the convection of the liquid in the tank will be aggravated, and eventually, the superheated lower liquid will rise rapidly and generate a large amount of boil-off gas (BOG). First, the surface of the LNG will continuously evaporate due to heat leakage in the storage tank, thus changing its original composition, density and temperature. Molar mass components evaporate first and then the heavier part. Both the lower and upper temperatures are slowly rising. The density of the lower layer decreases, and the density of the upper layer increases due to evaporation. This process is called LNG stratification, as shown in stage 1 in Figure 1a. Second, under the influence of heat leakage from the bottom, the liquid in the lower layer of the storage tank is evaporated through the layered upper surface partition. With heat transfer and convection, the lower layers gradually become overheated, and the density of the lower layers continues to decrease. In step 2, the bottom layer temperature rapidly rises to a maximum value and then drops. In summary, stratification occurs gradually in steps 1 and 2. The lower layer of liquid penetrates slowly but steadily into the upper layer. This process is shown in Figure $1 \mathrm{~b}$ and is called LNG interlayer penetration. Third, all accumulated 
superheat in the lower layer is released from the free surface by evaporation, resulting in rapid mixing of the lower and upper layers. In step 3, the amount of BOG suddenly rises linearly and starts to decrease after reaching the maximum value. Other parameters, such as the temperature and density of the upper and lower layers, tend to stabilize after gradually approaching, and each stabilizes at a specific value. The drastic change in parameters during this time is the biggest challenge for LNG storage tanks. This process is shown in Figure 1c, which is called LNG rollover. Finally, the LNG in the tank reached a new uniform equilibrium in temperature and density, as shown in Figure 1d. In step 4 , the parameters of the upper and lower layers tend to approach stability, the amount of BOG gradually decreases to a minimum, and the LNG storage tank returns to a new thermodynamic equilibrium.
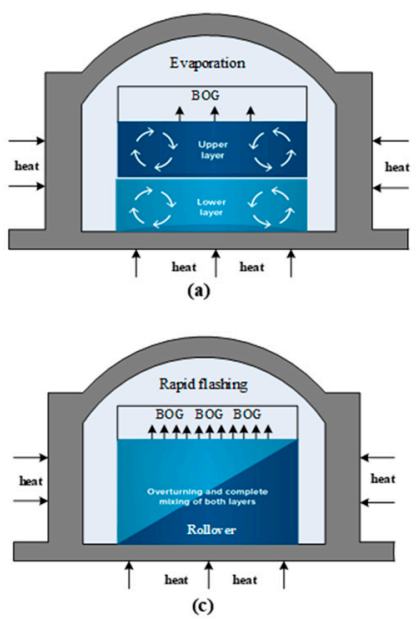

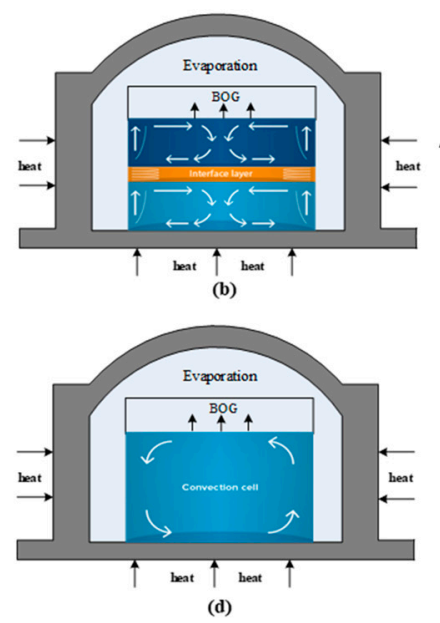

(a) physical model of storage tanks

(b) the variation trend of each parameter

Figure 1. Schematic diagram of LNG from stratification to rollover in tanks: (a) physical model of storage tanks; (b) the variation trend of each parameter.

In the actual project of the LNG storage tank, there will be a set of monitoring systems to observe the changes in the density, pressure, temperature and other parameters in the tank. The measuring points of the monitoring system are evenly distributed in the height direction of the storage tank, and the storage tank is divided into a number of continuous, etc. In the high-rise, as shown in Figure 1, the tumbling in the storage tank can be seen as the violent mixing of LNG between two adjacent layers. Therefore, the physical model of the storage tank is simplified as follows: (1) taking a $16 \times 104 \mathrm{~m}^{3}$ LNG storage tank as an example, ignoring the influence of the wall thickness of the tank, the diameter of the tank is $80 \mathrm{~m}$, and the height of the upper and lower liquid layers is $2 \mathrm{~m}$, respectively, so the two adjacent liquid phases are intercepted to establish a two-dimensional model; (2) only study the tumbling of the liquid phase fluid in the tank, and the liquid phase fluid is an incompressible Newtonian fluid, without considering the influence of the gas phase fluid; (3) the heat leakage from the sidewall of the storage tank is smaller than the heat leakage at the bottom, and the impact is smaller. The heat leakage from the external environment is simplified as the heat leakage at the bottom of the lower liquid phase; (4) since the tumbling process of LNG in the storage tank is approximately axisymmetric, only the left half of the centerline of the two layers is taken. The abscissa $x$ is the radial direction of the storage tank, and the ordinate $\mathrm{z}$ is the height direction of the tank. Finally, select the upper LNG center and lower center at the centerline of the storage tank, the center of the layered interface and the boundary point to monitor the density and velocity, respectively. 


\section{Numerical Implementation}

\subsection{Governing Equations}

The basic governing equation of fluid flow is the constraint condition that liquid flow must meet. In addition, LNG is a multicomponent material. To meet the multicomponent transport equation, turbulent motion is involved in the internal rolling process of the storage tank, and a turbulent model needs to be set up. The followings are a set of flow control equations in a rectangular coordinate system [41].

Mass conservation equation:

$$
\frac{\partial u}{\partial x}+\frac{\partial v}{\partial y}=0
$$

Momentum conservation equation:

$$
\frac{\partial u_{i}}{\partial \tau}+u_{j} \frac{\partial u_{i}}{\partial x_{i}}=-\frac{1}{\rho} \frac{\partial p}{\partial x_{i}}+\left(v+v_{t}\right) \nabla^{2} u_{i}+F_{i}
$$

Energy conservation equation:

$$
\frac{\partial t}{\partial \tau}+u \frac{\partial u}{\partial x}+v \frac{\partial t}{\partial y}=\left(\frac{\lambda}{c_{p}}+\frac{\eta_{t}}{\sigma_{t}}\right)\left(\frac{\partial^{2} t}{\partial x^{2}}+\frac{\partial^{2} t}{\partial y^{2}}\right)
$$

Composition equation:

$$
\frac{\partial S}{\partial \tau}+u \frac{\partial S}{\partial x}+v \frac{\partial S}{\partial y}=\left(\frac{v}{S_{C}}+\frac{v_{t}}{\sigma_{C}}\right)\left(\frac{\partial^{2} t}{\partial x^{2}}+\frac{\partial^{2} t}{\partial x^{2}}\right)
$$

$k-\varepsilon$ equation:

$$
\left\{\begin{array}{l}
\frac{\partial}{\partial \tau}(\rho k)+\frac{\partial}{\partial x_{i}}\left(\rho k u_{i}\right)=\frac{\partial}{\partial x_{j}}\left[\left(\mu+\frac{\mu_{t}}{1.0}\right) \frac{\partial k}{\partial x_{j}}\right]+G_{k}+G_{\varepsilon}-\rho \varepsilon \\
\frac{\partial}{\partial t}(\rho \varepsilon)+\frac{\partial}{\partial x_{i}}\left(\rho \varepsilon u_{i}\right)=\frac{\partial}{\partial x_{j}}\left[\left(\mu+\frac{\mu_{t}}{1.3}\right) \frac{\partial \varepsilon}{\partial x_{j}}\right]+1.44 \frac{\varepsilon}{k}\left(G_{k}+1.92 \varepsilon\right)-G_{\varepsilon}
\end{array}\right.
$$

where $i$ and $j$ are coordinate direction. $\rho, p$ and $\tau$ are density, pressure and time, respectively. $v$ and $v_{t}$ are the viscosity coefficient of laminar and turbulent flows. $F_{i}$ is the volume force of fluid in the unit direction. $u$ and $v$ are the velocities in the $x$ - and $y$-direction. $S$ and $\sigma$ are the mass fraction and diffusion coefficient of each component. $k$ is turbulent kinetic energy, $\varepsilon$ is turbulent kinetic energy dissipation rate. $G$ is the generic term of turbulent kinetic energy caused by mean velocity gradient.

\subsection{Computational Models with Grids}

The mixture model and transient state in Fluent 17.9 were selected for the solution. The software sets the center points of the upper and lower layers of the model centerline storage, as well as the center points of the layered interface and the model boundary points to monitor changes in speed and density. The model is simplified to a two-dimensional plane structure, and the upper and lower control bodies adopt structured grids, and the grids are encrypted in the boundary layer after the partition and the partition are added. The grids of other models with partition structures are still expanded according to this grid density except for boundary refinement. The simplified method, meshing and governing equation of the model are consistent with the previous verification, and the baffle is simplified to a baffle without thickness and without heat transfer. The grid independence verification result is that the measurement speed of the interface at the center points of the upper and lower layers is the evaluation standard, and the number of 42,000 grids is selected as the calculation standard. Its speed is $0.011 \mathrm{~m} / \mathrm{s}$, and there is no change in subsequent grid growth. 


\subsection{Assumptions and Boundary Conditions}

In order to reduce the complexity of the model, this paper has simplified the following four points by reducing the non-significant terms in the model to the physical model of layering and rolling in the LNG storage tank: (1) the model selects a two-dimensional model and ignores the wall thickness of the inner tank. (2) do not consider the gas phase, only the liquid phase; (3) assuming the initial conditions, that is, stratification has occurred, study the temperature and velocity changes of the liquid in the LNG tank after the stratification; (4) it is assumed that the flow of LNG complies with Newton's internal friction law, and the effects of flow and viscous dissipation are not considered. Since the mixing flow process of the LNG liquid in the storage tank between the liquid phases after layer formation is not affected by external forces, a gravity acceleration is set during the simulation.

The boundary conditions: the initial temperature of the upper layer is $113.3 \mathrm{~K}$, the temperature of the lower layer is $114.2 \mathrm{~K}$, the pressure in the storage tank is $0.2 \mathrm{MPa}$, the heat leakage at the bottom of the storage tank is $10 \mathrm{~W} / \mathrm{m}^{2}$, the total height of the liquid in the storage tank is $4 \mathrm{~m}$, and the upper and lower layers are each $2 \mathrm{~m}$. The model does not consider wall thickness, and simplifies the baffle into a wall without thickness and does not consider heat transfer. The densities of the upper and lower layers are calculated from Table 1. For the sidewalls and bottom walls are specified as follows: (1) the velocity is no-slip condition; (2) $\partial S \partial y=0$; (3) $\partial k \partial y=0$. The initial conditions for the rollover model of LNG storage tank are set as follows: (1) the initial temperature of the two layers of LNG is set, respectively, and the initial temperature is fixed; (2) the density of the two types of LNG is temperature-dependent and meets different relationships, respectively. There is a density difference between the density of the upper and lower layered LNG; (3) the initial velocity of the fluid is 0 . In the process of the evolution of LNG liquid from stratification to rollover in the storage tank, the movement condition at the interface is relatively representative. The liquid in the stable storage LNG tank is a stable natural convective circulation, while the liquid in the tumbling phase is a violent eddy and turbulent motion. Therefore, it is possible to judge whether the tank is in the rollover process by judging whether there is turbulence.

\section{Results and Discussion}

\subsection{Numerical Model Validation}

Before the numerical simulations, the model validation was carried out and compared with the experimental data reported by Bates et al. [27], and those rollover experiments were conducted by several gas companies. These data include LNG temperature and density measurement in the tanks under different stratification conditions. According to the survey, the reported accuracy of the experimental data was about $1.2 \%$ to $7.2 \%$ based on the inaccuracy of the temperature and density measuring equipment. The data error during the stratification to rollover is small, and the data error measured during the rollover is large. This was due to the immaturity and high-cost of the transient measurement technology at the time, and the average value of the process was used to record the dynamic rollover state during data measurement. As shown in Figure 2, using numerical simulation to reimplement the experimental and operating conditions, the temperature distribution in the numerical simulation is a good way to summarize the experimental results and visualize from the stratification to rollover in tanks. The experiment and simulation describe that the fluid in the storage tank due to the heat leakage at the bottom is first of high-temperature in the lower layer and low-temperature in the upper layer. Under the action of gravity and thermal convection, it gradually evolves and finally rolls over. The results show that the numerical calculation results are compared with the experimental data in the literature, and the changes in temperature are similar, and the difference between the calculated values and the experimental values is not more than $6.8 \%$. The surface of the LNG will continuously evaporate due to heat leakage in the storage tank, thus changing its original composition, density and temperature. Both the lower and upper temperatures are slowly 
rising. This process is called LNG stratification, which is where the verification process is started. Under the influence of heat leakage from the bottom, the liquid in the lower layer of the storage tank is evaporated through the layered upper surface partition. With heat transfer and convection, the lower layers gradually become overheated, and the density of the lower layers continues to decrease. The bottom layer temperature rapidly rises to a maximum value and then drops. The lower layer of liquid penetrates slowly but steadily into the upper layer based on the different densities of the upper and lower layers. All accumulated superheat in the lower layer is released from the free surface by evaporation, resulting in rapid mixing of the lower and upper layers (12-48 h). The drastic change in parameters during this time is the biggest challenge for LNG storage tanks, which is called LNG rollover ( $48-60 \mathrm{~h}$ ). Finally, the LNG in the tank reached a new uniform equilibrium in temperature and density.

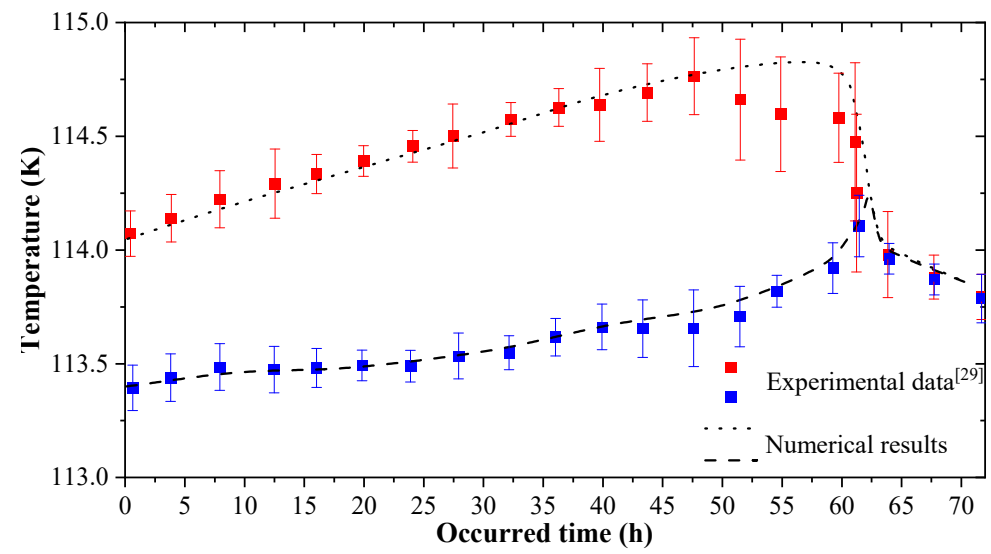

(a)

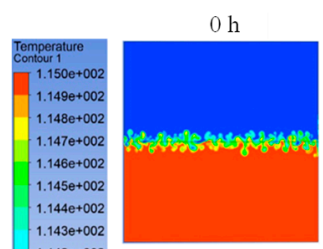

$58 \mathrm{~h}$

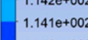

$1.141 e+002$
$1.140 e+002$
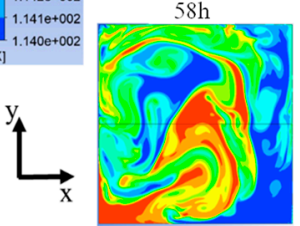

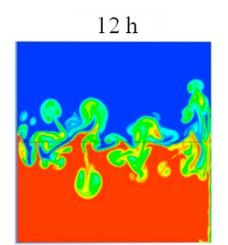

$60 \mathrm{~h}$

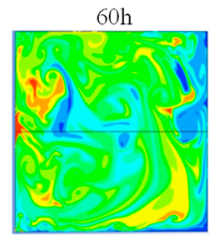

(b)
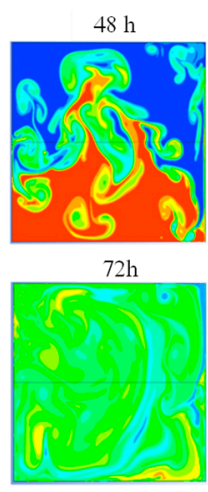

Figure 2. Comparison between the numerical results and experimental data. (a) data comparison; (b) process simulation.

\subsection{Effects of Density Difference, Heat Leakage and Stratification on Rollover}

This study is aimed at the evolution of the rollover phenomenon when LNG liquids of different densities from different regions are injected into the storage tanks, or when the density difference between the upper and lower layers is caused by the precipitation of impurities in the aging LNG after some time. The magnitude of the convection rollover of the upper and lower layers caused by the density difference is expressed by the speed of the interface monitoring point. In the five cases where the average density difference between the upper and lower layers of the liquid in the storage tank is $5 \mathrm{~kg} / \mathrm{m}^{3}$ to $0.2 \mathrm{~kg} / \mathrm{m}^{3}$, respectively, the duration of the rolling activity under different stratification density difference, the maximum velocity and the time required on the boundary surface of the rolling under different stratification density difference are shown in Figure 3. It can be concluded that in the same tank with the same external conditions such as diameter and volume, the greater the density difference of the layered LNG liquid, the earlier the boundary surface begins to fluctuate, the earlier the maximum velocity at the interface appears, and the greater the maximum velocity at the boundary surface, the more likely it is to roll, and the more urgent and intense in the rollover process. 


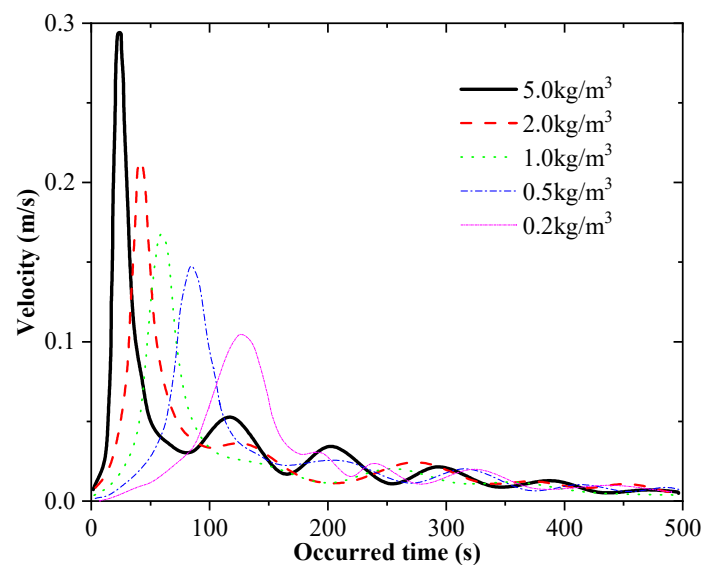

(a)

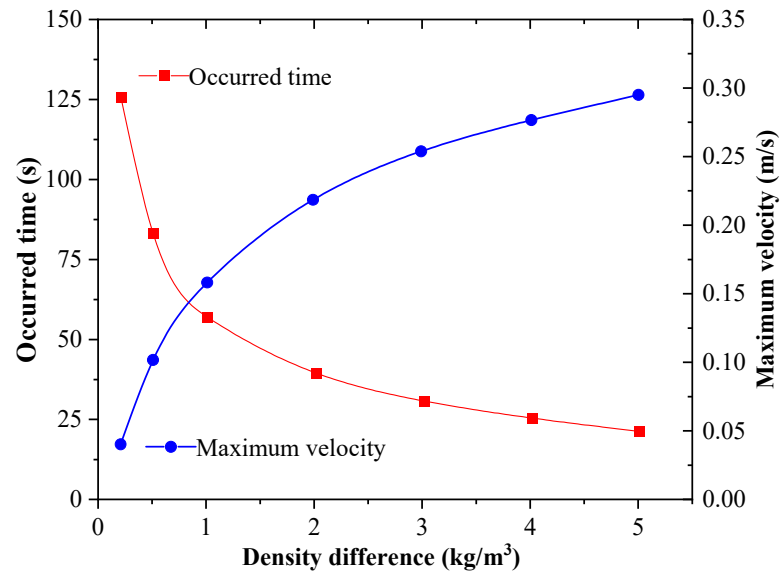

(b)

Figure 3. The variation of density difference occurred at time and velocity on the rollover process. (a) Density difference effect; (b) occurred time and velocity.

In practice, the layered state of the LNG liquid in the storage tank is various, and the height of the upper and lower layered layers will be very different. Therefore, under the condition of fixed density difference, the influence of the total layer height and the ratio of the upper layer height to the total layer height in the layering parameters were studied. The relevant results are shown in Figure 4 as follows: First, in those cases where the total height of the stratification changes, 5 cases in the interval from $1 \mathrm{~m}$ to $10 \mathrm{~m}$ of the height of the stratification are calculated. It can be concluded that the larger the total height of the stratification, the more severe the rollover occurs, the longer the duration, and the greater the maximum velocity that the layer interface can achieve. Second, the influence of the percentage of the upper layer height to the total layer height on the rollover process was calculated in 9 cases (10-90\%). The results show that the maximum velocity of the interface is higher when the ratio of the upper layer height to the total layer height is $20 \%$ to $50 \%$, which indicates that the rolling in this area is the most violent. As the proportion of the height of the upper layer increases, the time of the rollover is always increasing. It can be inferred that the smaller the proportion of the upper level is, the more likely it is to rollover in the short-term and the more harmful it is.

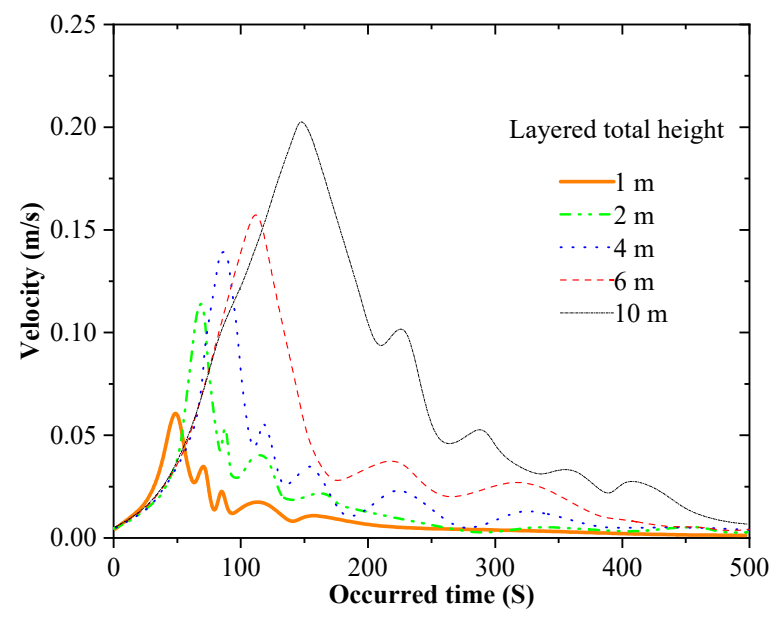

(a)

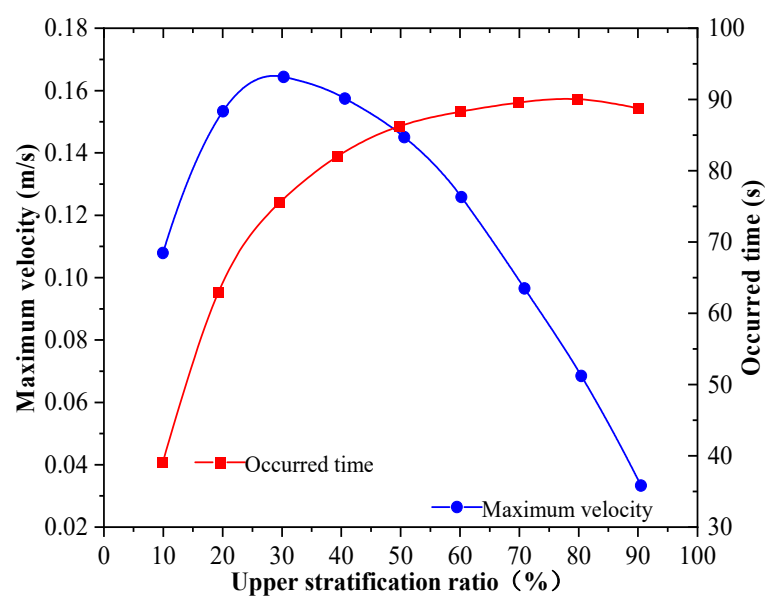

(b)

Figure 4. The variation of layered total height, the upper layered ratio on the rollover process. (a) Layered total height; (b) occurred time and the upper layered ratio. 
The temperature difference between the bottom and the outer wall of the LNG cryogenic storage tank relative to the liquid in the tank is relatively large, which is much larger than the temperature fluctuation of the outdoor environment, and the influence of outdoor air temperature fluctuation can be ignored. The heat transfer form of the bottom of the storage tank and the wall of the storage tank is mainly that the heat is transferred to the internal tank through the outer tank and the cold insulation material in the form of heat conduction. Therefore, by assuming a fixed heat flux, a study was conducted on the effects of heat leakage from the bottom and wall facing the tank on the rollover process. Figures 5 and 6 show the results of different heat leakage conditions in the case of heat leakage from the bottom of the storage tank and heat leakage from the outer wall surface of the storage tank. With the increase of the heat leakage at the bottom, the velocity increases during the rollover, and the tumbling time decreases. Under different heat leakage from the sidewall, the maximum velocity and time of rollover do not change much. In the case of a small amount of heat leakage, the time difference between the bottom leakage heat and the sidewall leakage caused by the rollover is not too much, but the rolling velocity is different. With the increase of the heat leakage, the influence of the sidewall heat leakage, on the whole, is getting smaller and smaller; the time and severity of the rollover are mainly affected by the bottom heat leakage.

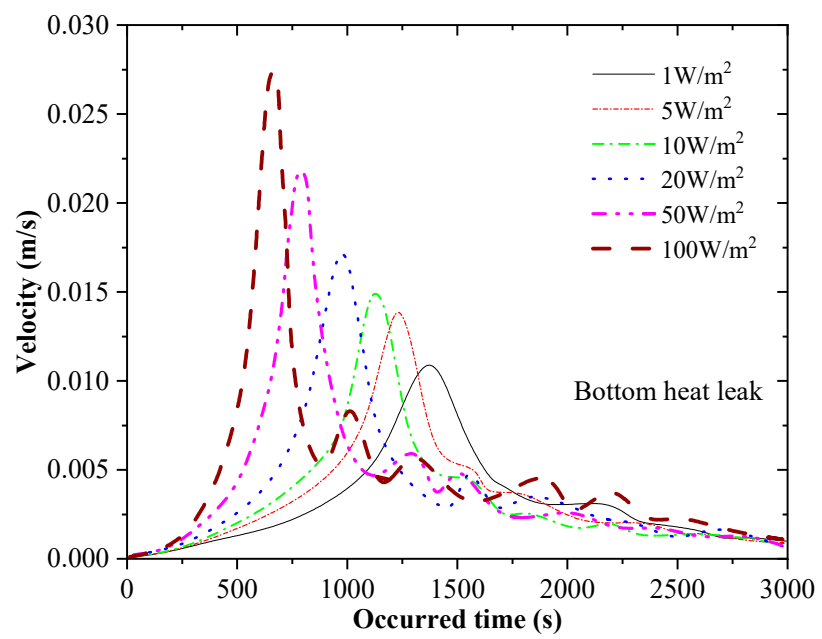

Figure 5. Effect of heat leak at the bottom of the tank on the rollover process.

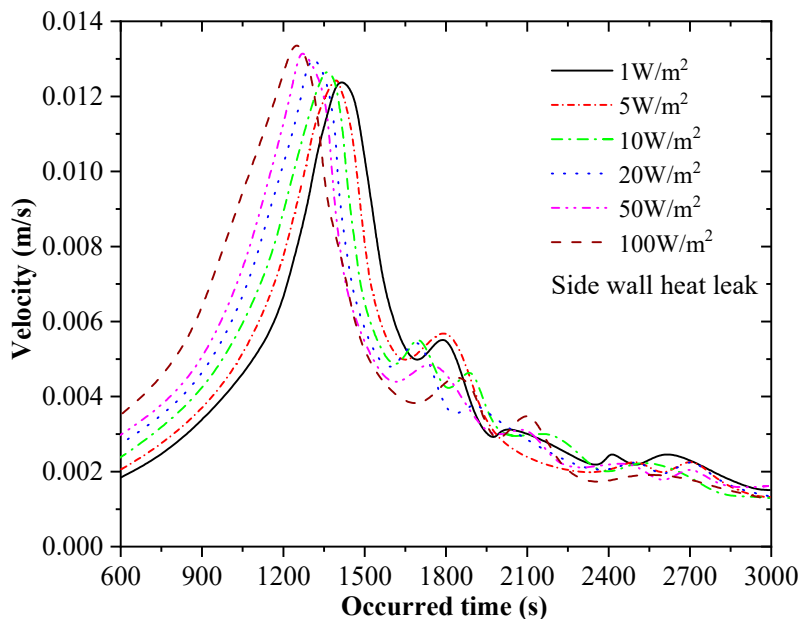

Figure 6. Effect of heat leak at the wall of the tank on the rollover process. 


\subsection{Effects of Baffle Structure on Rollover}

Heat leakage and stratification are naturally unavoidable in the storage tank. Therefore, the structure of the storage tank needs to be artificially changed to alleviate the occurrence of liquid rolling after layering. Moreover, considering that the cost, construction and shape of the storage tank are calculated and applied in practice, this study only considered the influence of tank internal baffles on the rollover process after liquid stratification in the case that the structure outside the storage tank and the loading volume remains unchanged. The model studied is that the total height of the liquid is $4 \mathrm{~m}$, and the upper and lower layers are $2 \mathrm{~m}$, respectively, without considering the wall thickness, and the baffle is simplified into a wall surface without thickness and without considering the heat transfer. The density difference between the upper and lower layers is about $1 \mathrm{~kg} / \mathrm{m}^{3}$. The results show that compared with the reference structure without the baffle, adding the baffle can appropriately delay the time that the rolling interface can reach the maximum velocity. However, the rollover time is approximately the same under different baffle lengths, and the maximum velocity corresponding to the baffle is the smallest when the baffle length is $2 \mathrm{~m}$.

Figures 7 and 8 show the baffle length and velocity distribution of the model with the baffles structure. It can be seen that small vortex mixing occurs first, which increases the liquid velocity and causes disturbances between layers. Due to the influence of the baffle, the tumbling vortex at the tank wall began to disturb the nearby liquid and developed toward the center. As the center vortex increased, the number of vortexes increased, and vortices appeared inside the liquid. During the tumbling process, the speed is gradually increasing, and the mixing and agitation between the upper and lower layers are vigorously ongoing. Finally, the entire flow field started to stabilize, and the liquid mixing speed became slower and slower.

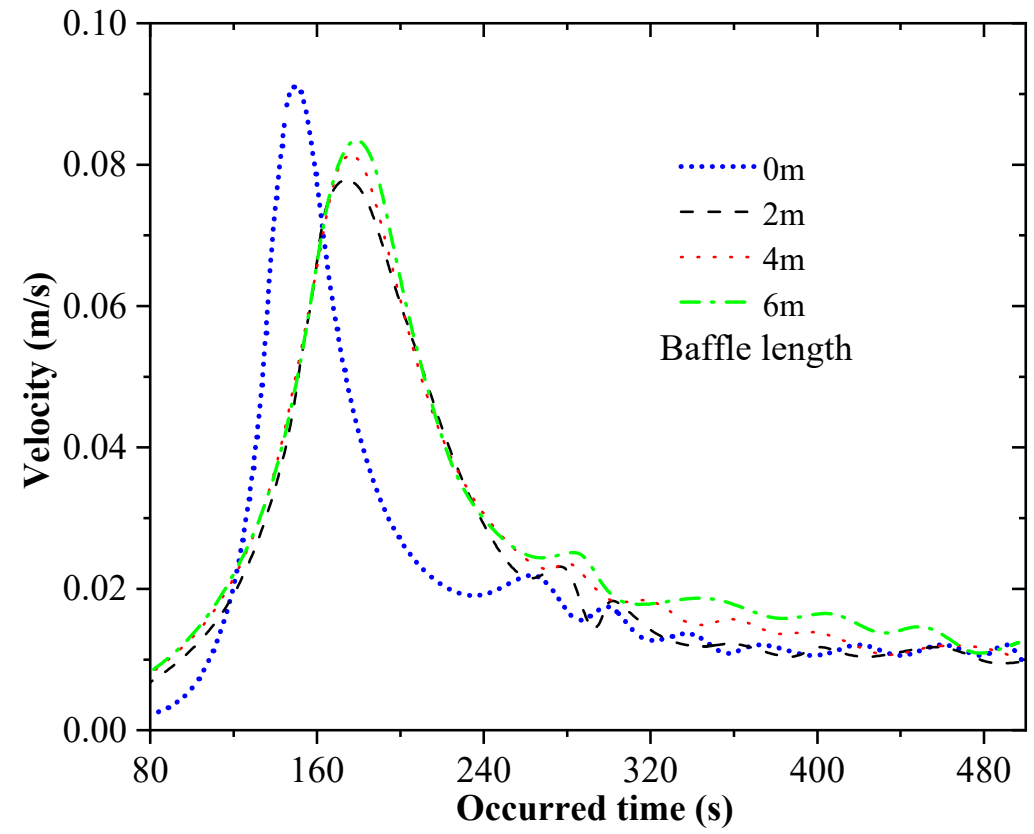

Figure 7. Effect of baffle length of the tank on the rollover process. 


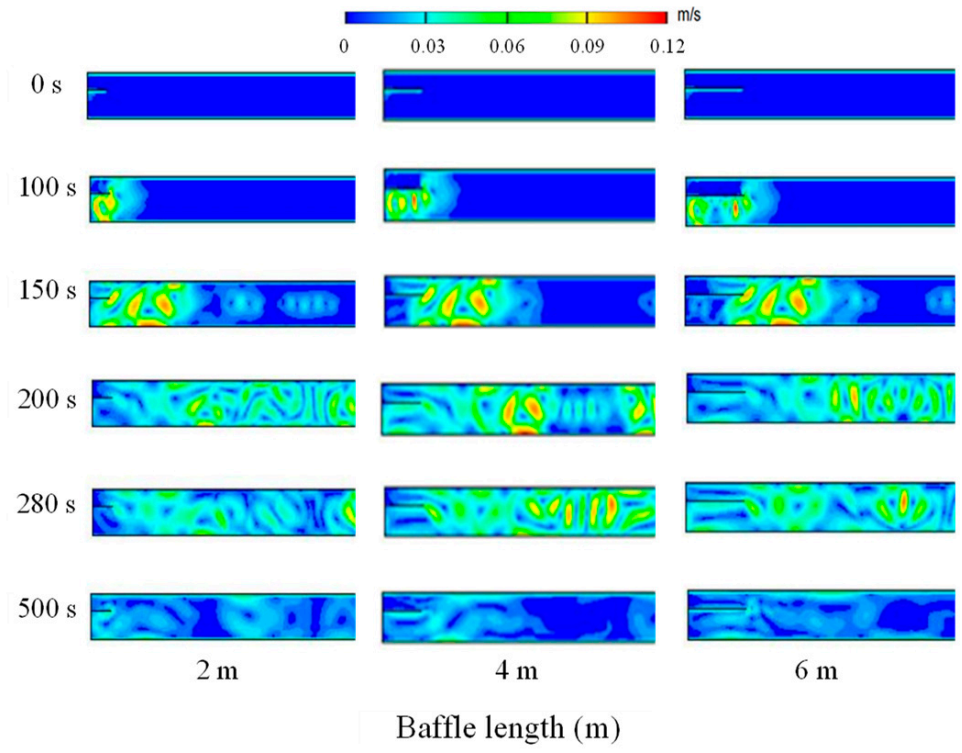

Figure 8. Velocity distribution in the tank with baffles structure.

Figure 9 shows the effect of the installation position of the baffles on the liquid rollover process in the storage tank. The middle position of the upper and lower layer was set to 0 installation height, and 8 cases from $-0.75 \mathrm{~m}$ to $0.75 \mathrm{~m}$ were calculated. The figure represents the installation scheme and position, and it can be concluded that the rollover time of the baffle at different installation heights is approximately equal, which indicates that different installation heights have little effect on the time of the rollover. Moreover, the maximum velocity corresponding to several structures is different. The maximum velocity corresponding to the baffles when the installation height is $0.5 \mathrm{~m}$ is the smallest.

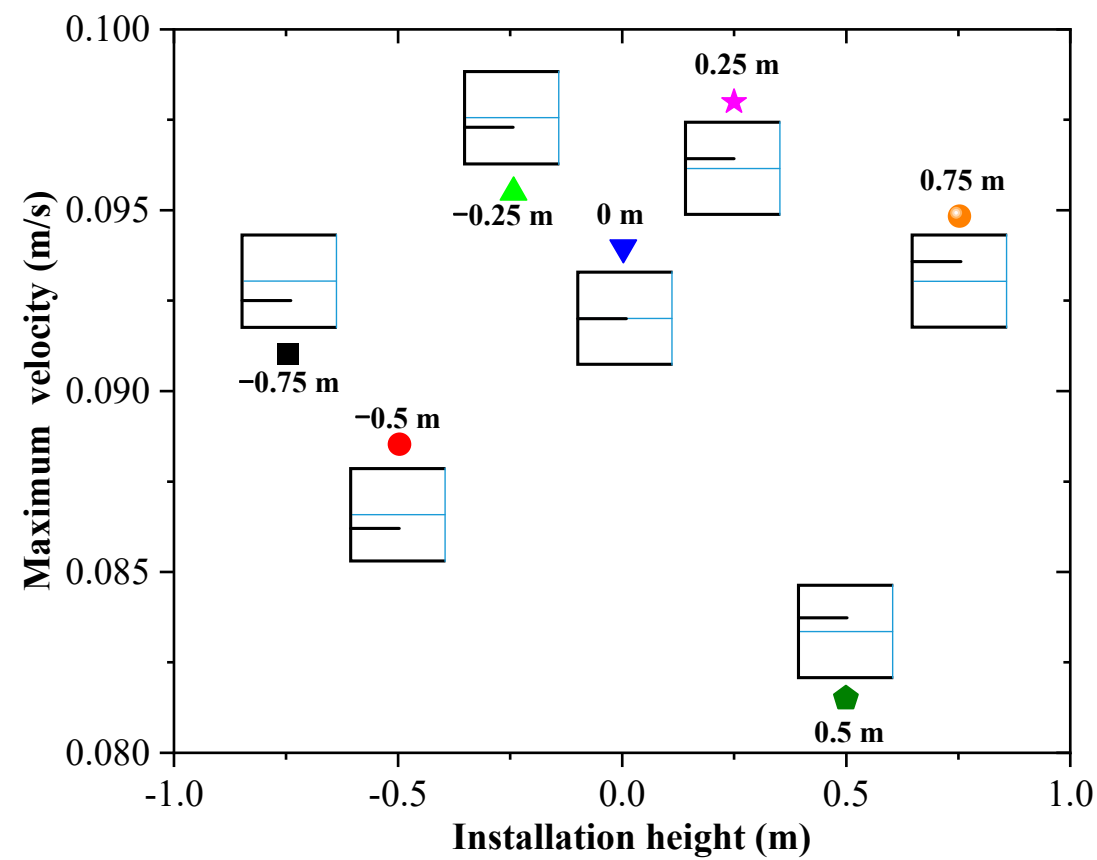

Figure 9. Effect of baffle installation height of the tank on the rollover process.

Finally, the suppression effect of the installation angle of the baffle on the rollover is studied, which is reflected in the time when the maximum velocity is reached and the start time, as shown in Figure 10. The model set a 0-degree angle with the parallel upper 
and lower boundary lines as the installation and stipulated that the installation angle of the partition counterclockwise was positive; otherwise, it was negative. The results are calculated under 11 conditions from -45 degrees to 45 degrees. Under different installation angles of the baffles, the occurrence time of the rollover in the storage tank is generally the same, but the corresponding maximum velocity is different, which means that the different angles have a certain inhibitory effect on the violent rollover in the storage tank. Moreover, the larger the installation angle, the larger the consumables of the baffles are, and it is not easy to fix. Finally, under various conditions, it is believed that under the installation condition of $+5^{\circ}$, it can effectively suppress the severity of rolling and reduce consumables.

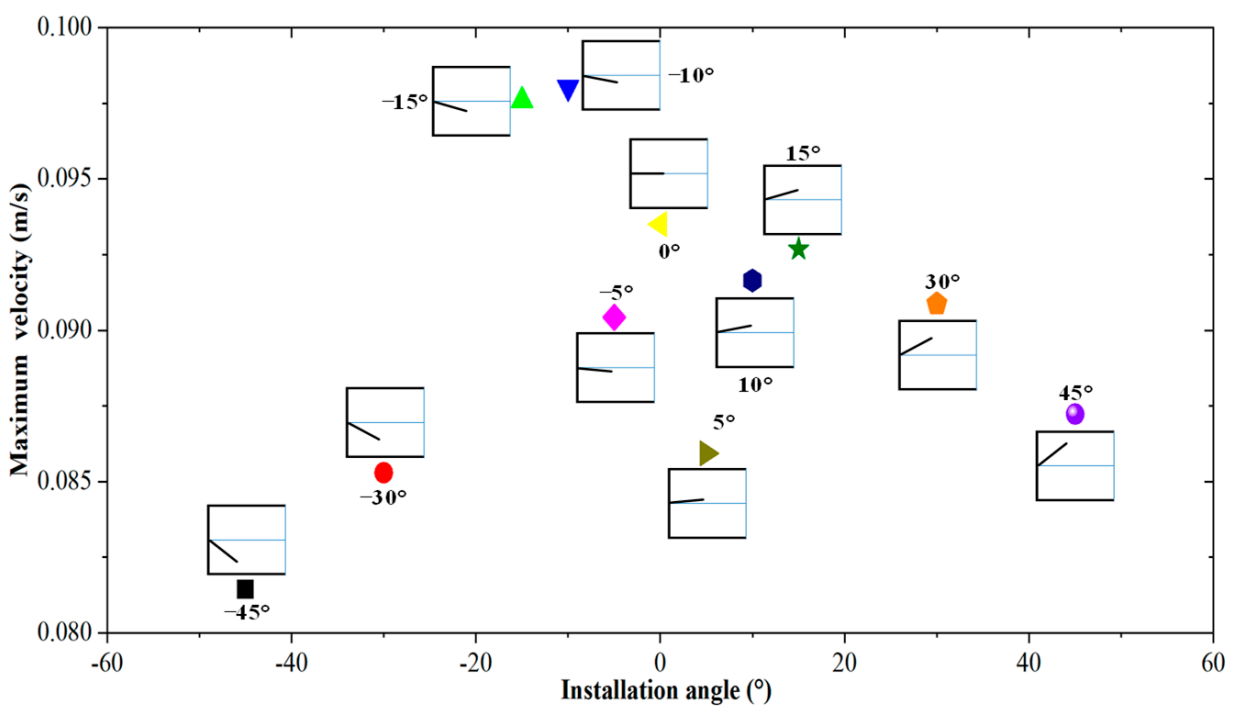

Figure 10. Effect of baffle installation angle of the tank on the rollover process.

\section{Conclusions}

In this paper, computational fluid dynamics technology is used to study the numerical simulation of the rollover process of LNG storage tanks after stratification and its influencing factors. In the simulation process, the characteristics of LNG multicomponent and variable physical properties were fully considered, and the influence of the density difference between upper and lower layers, layering parameters, heat leakage parameters, and the baffles structure on the rollover process was studied, respectively. Relevant conclusions are as follows:

(1) The degree of the tumbling of the LNG storage tank is mainly determined by the influence of the maximum velocity of the interface in the central area. The magnitude of its effect is mainly determined by the density difference between the upper and lower layers, while the density difference between the upper and lower layers is only affected by the heat leakage from the bottom;

(2) After the baffle is added, different baffle structures that have different boundary velocity fields will be formed. However, this velocity field only affects the severity of the rollover and does not affect the time when the rollover occurs. The time is only affected by the density difference;

(3) With the change of the distance between the baffles from the top and bottom of the layered interface and the installation angle, the trend of the rollover intensity is consistent. After comprehensive consideration, it is concluded that at $0.5 \mathrm{~m}$ above the stratified interface with the installation of the baffle at $5^{\circ}$ has the best inhibition effect on the rollover intensity.

Subsequent studies can be carried out from the following aspects: (1) the multiphase species transport model that is used to consider the miscible factor of the LNG mixture, which eliminates the unrealistic gravity separation in the stratification and tumbling 
phenomenon; (2) the influence of mass transfer and heat transfer at the gas-liquid and liquid-liquid interfaces and the effects of the interfacial surface variations are considered as a further study topic; (3) simulation of different injection methods to analyze the layered tumbling of LNG in the tank under the mixed charging mode.

Author Contributions: Z.W. conducted the numerical calculation and wrote the paper. F.H. analyzed the results and commented on the paper. W.L. gave some suggestions. Y.L. carried on project administration. All authors have read and agreed to the published version of the manuscript.

Funding: This work was funded by the National Natural Science Foundation of China (51906026), China Postdoctoral Science Foundation (2020M680928, 2020M670726), Natural Science Foundation of Liaoning Province (2020-BS-067), the Fundamental Research Funds for the Central Universities (3132019331, 3132019368).

Conflicts of Interest: The authors declare no conflict of interest.

\title{
Nomenclature
}

$\begin{array}{ll}c_{p} & \text { Specific heat capacity }\left(\mathrm{J} \cdot \mathrm{kg}^{-1} \cdot \mathrm{K}^{-1}\right) \\ F & \text { Volume force of fluid }\left(\mathrm{kg} \cdot \mathrm{m}^{-2}\right) \\ G & \text { Generic term of turbulent kinetic energy }\left(\mathrm{kg} \cdot \mathrm{m}^{2} \cdot \mathrm{s}^{-2}\right) \\ i & \text { Free coordinates in the Cartesian coordinate system } \\ j & \text { Free coordinates in the Cartesian coordinate system } \\ k & \text { Turbulent kinetic energy }\left(\mathrm{kg} \cdot \mathrm{m}^{-2} \cdot \mathrm{s}^{-1}\right) \\ P & \text { Pressure }(\mathrm{kPa}) \\ R e & \text { Reynolds Number } \\ S & \text { Mass fraction and diffusion coefficient } \\ T & \text { Temperature }(\mathrm{K}) \\ t & \text { Time }(\mathrm{s}) \\ u & \text { Velocities in the } \mathrm{x} \text {-direction }(\mathrm{m} / \mathrm{s}) \\ v & \text { Velocities in the y-direction }(\mathrm{m} / \mathrm{s}) \\ x & \text { Coordinate direction } \\ y & \text { Coordinate direction } \\ G \text { Greek symbols } & \\ \lambda & \text { Fluid thermal conductivity }\left(\mathrm{W} \cdot \mathrm{m}^{-1} \cdot \mathrm{K}^{-1}\right) \\ \mu & \text { Dynamic viscosity }\left(\mathrm{kg} \cdot \mathrm{m}^{-1} \cdot \mathrm{s}^{-1}\right) \\ \rho & \text { Density }\left(\mathrm{kg} \cdot \mathrm{m}^{-3}\right) \\ \tau & \text { Time }(\mathrm{s}) \\ \varepsilon & \text { Turbulent kinetic energy dissipation rate }\end{array}$

\author{
Abbreviations \\ BOG Boil-off gas \\ CFD Computational fluid dynamics \\ LNG Liquefied natural gas
}

\section{References}

1. Qadrdan, M.; Abeysekera, M.; Wu, J.; Jenkins, N.; Winter, B. Fundamentals of Natural Gas Networks. In The Future of Gas Networks; Springer: Cham, Switzerland, 2020; pp. 5-22.

2. Tutak, M.; Brodny, J.; Siwiec, D.; Ulewicz, R.; Bindzár, P. Studying the Level of Sustainable Energy Development of the European Union Countries and Their Similarity Based on the Economic and Demographic Potential. Energies 2020, 13, 6643. [CrossRef]

3. Hwang, S.-Y.; Kim, M.-S.; Lee, J.-H. Thermal Stress Analysis of Process Piping System Installed on LNG Vessel Subject to Hull Design Loads. J. Mar. Sci. Eng. 2020, 8, 926. [CrossRef]

4. Guze, S.; Wawrzynski, W.; Wilczynski, P. Determination of Parameters Describing the Risk Areas of Ships Chaotic Rolling on the Example of LNG Carrier and OSV Vessel. J. Mar. Sci. Eng. 2020, 8, 91. [CrossRef]

5. Chun, D.-H.; Roh, M.-I.; Ham, S.-H. Optimum Arrangement Design of Mastic Ropes for Membrane-Type LNG Tanks Considering the Flatness of Thermal Insulation Panel and Production Cost. J. Mar. Sci. Eng. 2020, 8, 353. [CrossRef]

6. Park, N.K.; Park, S.K. A Study on the Estimation of Facilities in LNG Bunkering Terminal by Simulation—Busan Port Case. J. Mar. Sci. Eng. 2019, 7, 354. [CrossRef] 
7. Zhao, Z.; Zhang, X.; Li, Z. Tank-Level Control of Liquefied Natural Gas Carrier Based on Gaussian Function Nonlinear Decoration. J. Mar. Sci. Eng. 2020, 8, 695. [CrossRef]

8. Nirbito, W.; Budiyanto, M.A.; Muliadi, R. Performance Analysis of Combined Cycle with Air Breathing Derivative Gas Turbine, Heat Recovery Steam Generator, and Steam Turbine as LNG Tanker Main Engine Propulsion System. J. Mar. Sci. Eng. $2020,8,726$. [CrossRef]

9. Wang, Z.; Cai, W.; Shen, S.; Hong, W.; Wang, X. Numerical investigation of stratification and rollover characteristics for LNG tanks. In Proceedings of the 14th IEEE Conference on Industrial Electronics and Applications, Xi'an, China, 19-21 June 2019; pp. 324-329.

10. Ferrín, J.L.; Pérez-Pérez, L.J. Numerical simulation of natural convection and boil-off in a small size pressurized LNG storage tank. Comput. Chem. Eng. 2020, 138, 106840.

11. Scurlock, R.G. Stratification, Rollover and Handling of LNG, LPG and Other Cryogenic Liquid Mixtures; Springer: Cham, Switzerland, 2015; pp. 40-133.

12. Haddar, M.; Hammami, M.; Baccar, M. Numerical study of steady natural convection in a liquefied natural gas cylindrical storage tank equipped with baffles. Proc. Inst. Mech. Eng. Part A J. Power Energy 2019, 234, 709-721. [CrossRef]

13. Germeles, A.E. A model for LNG tank rollover. In Advances in Cryogenic Engineering; Springer: Boston, MA, USA, 1960; pp. 326-336.

14. Baker, N.; Creed, M. Stratification and rollover in liquefied natural gas storage tanks. Process Saf. Environ. Prot. 1996, 74, 25-30.

15. Bralewski, A.; Wolanin, J. Analysis of threats involving Liquefied Natural Gas (LNG)—Review of literature sources. Saf. Fire Technol. 2019, 53, 32-53. [CrossRef]

16. Chatterjee, N.; Geist, J.M. Effects of stratification on boil-off rates in LNG tanks. Pipeline Gas J. 1972, $199,40-45$.

17. Heestand, J.; Shipman, C.W.; Meader, J.W. A predictive model for rollover in stratified LNG tanks. AlChE J. 1983, 29, 199-207. [CrossRef]

18. Munakata, T.; Lior, N.; Tanasawa, I. A study of double-diffusive rollover in cylinder enclosures. ASME 1995, 317, $279-291$.

19. Koyama, K. CFD Simulation on LNG Storage Tank to Improve Safety and Reduce Cost; Springer: Tokyo, Japan, 2007.

20. Li, Y.; Li, Z.; Wang, W. Simulating on rollover phenomenon in LNG storage tanks and determination of the rollover threshold. J. Loss Prev. Process. Ind. 2015, 37, 132-142. [CrossRef]

21. Migliore, C.; Salehi, A.; Vesovic, V. A non-equilibrium approach to modeling the weathering of stored Liquefied Natural Gas (LNG). Energy 2017, 124, 684-692. [CrossRef]

22. Wang, Z; Sharafian, A.; Mérida, W. Non-equilibrium thermodynamic model for liquefied natural gas storage tanks. Energy 2020, 190, 116412. [CrossRef]

23. Sugawara, Y.; Kubota, A.; Muraki, S. Rollover test in LNG storage tank and simulation model. In Advances in Cryogenic Engineering; Springer: Boston, MA, USA, 1984; pp. 805-811.

24. Muro, M. Experimental and analytical study of the rollover phenomenon using LNG. In Proceedings of the International Cryogenic Engineering Conference, Berlin, Germany, 22-25 April 1986; pp. 633-637.

25. Marcel, O. Measurement of the velocity of natural convection movements in an LNG storage tank. In Proceedings of the Gas Technology Conference, Amsterdam, The Netherlands, 21-22 May 1990; pp. 305-312.

26. Munakata, T.; Tanasawa, I. Numerical Study on Effect of Initial Concentration Difference on Onset of Rollover. Trans. Jpn. Soc. Mech. Eng. 1994, 60, 3512-3518. [CrossRef]

27. Tansawa, I. Experimental Techniques in Natural Convection. Exp. Therm. Fluid Sci. 1995, 10, 403518. [CrossRef]

28. Bates, S.; Morrison, D.S. Modelling the behaviour of stratified liquid natural gas in storage tanks: A study of the rollover phenomenon. Int. J. Heat Mass Transf. 1997, 40, 1875-1884. [CrossRef]

29. Gorieu, O.; Uznanski, D.; DuPont, P. How to operate LNG terminals with flexibility/safety despite the diversification of unloaded LNG qualities. In Proceedings of the 14th International Conference and Exhibition of Liquefied Natural Gas, Doha, Qatar, 21-24 March 2004; pp. 1-10.

30. Dai, J.; Ang, K.K.; Jin, J.; Wang, C.M.; Hellan, Ø.; Watn, A. Large Floating Structure with Free-Floating, Self-Stabilizing Tanks for Hydrocarbon Storage. Energy 2019, 12, 3487. [CrossRef]

31. Zhao, Z.; Zhou, Y.; Ma, X.; Chen, X.; Li, S.; Yang, S. Effect of Different Zigzag Channel Shapes of PCHEs on Heat Transfer Performance of Supercritical LNG. Energy 2019, 12, 2085. [CrossRef]

32. Wu, X.; Li, C.; He, Y.; Jia, W. Dynamic Modeling of the Two-Phase Leakage Process of Natural Gas Liquid Storage Tanks. Energy 2017, 10, 1399. [CrossRef]

33. Zakaria, Z.; Kamarulzaman, K.; Samsuri, A. Rollover phenomena in liquefied natural gas storage: Analysis on heat and pressure distribution through CFD simulation. Int. J. Innov. Eng. Technol. 2017, 8, 392-400.

34. Degawa, T.; Fukue, S.; Uchiyama, T.; Ishikawa, A.; Motoyama, K. Behavior of a Jet Issuing Diagonally Upward into Two-Layer Density-Stratified Fluid in a Cylindrical Tank. J. Flow Control. Meas. Vis. 2017, 5, 51-64. [CrossRef]

35. Zhao, B.; Han, S.; Xu, L.; Shi, C.; Gao, D.; Zhang, Y.D. Rollover Mechanism Methodology of LNG Tank with Gas-Liquid Stratification Based on Curvelet Finite Element Method and Large Eddy Simulation Technology. J. Appl. Fluid Mech. 2018, 11, 779-786. [CrossRef]

36. Sha, W.; Ren, J.; Wang, C.; Bi, M.; Bo, Y. Dynamic characteristics of the initial interface in stratified multi-composition liquid tanks during rollover. App. Therm. Eng. 2018, 145, 396-406. [CrossRef] 
37. Hubert, A.; Dembele, S.; Denissenko, P.; Wen, J. Predicting Liquefied Natural Gas (LNG) rollovers using Computational Fluid Dynamics. J. Loss Prev. Process. Ind. 2019, 62, 103922. [CrossRef]

38. Huerta, F.; Vesovic, V. A realistic vapour phase heat transfer model for the weathering of LNG stored in large tanks. Energy 2019, 174, 280-291. [CrossRef]

39. Ovidi, F.; Pagni, E.; Landucci, G.; Galletti, C. Numerical study of pressure build-up in vertical tanks for cryogenic flammables storage. App. Therm. Eng. 2019, 161, 114079. [CrossRef]

40. Yaws, C.L. Chemical Properties Handbook: Physical, Thermodynamic, Environmental, Transport, Safety, and Health Related Properties for Organic and Inorganic Chemicals; McGraw-Hill: New York, NY, USA, 1999.

41. Saleem, A.; Farooq, S.; Karimi, I.A.; Banerjee, R. CFD Analysis of Stratification and Rollover Phenomena in an Industrial-Scale LNG Storage Tank. Ind. Eng. Chem. Res. 2020, 59, 14126-14144. [CrossRef] 